\title{
A Novel Joint Support Vector Machine - Cubature Kalman Filtering Method for Adaptive State of Charge Prediction of Lithium-Ion Batteries
}

\author{
Qianqian Song ${ }^{1}$, Shunli Wang ${ }^{1, *}$, Wenhua $X u^{1}$, Yanhua Shao ${ }^{1}$, Carlos Fernandez ${ }^{2}$ \\ ${ }^{1}$ School of Information Engineering, Southwest University of Science and Technology, Mianyang \\ 621010, China; \\ ${ }^{2}$ School of +Pharmacy and Life Sciences, Robert Gordon University, Aberdeen AB10-7GJ, UK. \\ *E-mail: wangshunli@swust.edu.cn
}

doi: $10.20964 / 2021.08 .26$

Received: 11 April 2021 / Accepted: 1 June 2021 / Published: 30 June 2021

\begin{abstract}
Accurate estimation of SOC of lithium-ion batteries has always been an important work in the battery management system. However, it is often very difficult to accurately estimate the SOC of lithium-ion batteries. Therefore, a novel joint support vector machine - cubature Kalman filtering (SVM-CKF) method is proposed in this paper. SVM is used to train the output data of the CKF algorithm to obtain the model. Meanwhile, the output data of the model is used to compensate the original SOC, to obtain a more accurate estimate of SOC. After the SVM-CKF algorithm is introduced, the amount of data needed for prediction is reduced. By using Beijing Bus Dynamic Stress Test (BBDST) and the Dynamic Stress Test (DST) condition to verify the training model, the results show that the SVM-CKF algorithm can significantly improve the estimation accuracy of Lithium-ion battery SOC, and the maximum error of SOC prediction for BBDST condition is $0.800 \%$, which is reduced by $0.500 \%$ compared with CKF algorithm. The maximum error of SOC prediction under DST condition is about $0.450 \%$, which is $1.350 \%$ less than that of the CKF algorithm. The overall algorithm has a great improvement in generalization ability, which lays a foundation for subsequent research on SOC prediction.
\end{abstract}

Keywords: lithium-ion battery; Thevenin model; state of charge; support vector machine; cubature Kalman filter

\section{$\underline{\text { FULL TEXT }}$}

(C) 2021 The Authors. Published by ESG (www.electrochemsci.org). This article is an open access article distributed under the terms and conditions of the Creative Commons Attribution license (http://creativecommons.org/licenses/by/4.0/). 